\title{
Effects of home nest stimuli on the emotional response of preweanling rats to an unfamiliar environment
}

\author{
MICHAEL A. SIEGEL, RICK RICHARDSON, and BYRON A. CAMPBELL \\ Princeton University, Princeton, New Jersey
}

\begin{abstract}
A recent study (Richardson, Siegel, \& Campbell, in press) demonstrated that the presence of an anesthetized dam has a marked calming effect on the emotional responses of young rats between 16 and 30 days of age to separation from their home cage and placement in an unfamiliar environment, but has no effect on adult emotionality. With elevated heart rate (HR) as an index of fear, the present investigation assessed the relative contribution of the olfactory and thermotactile properties of the lactating dam in such fear reduction in 16-day-old rat pups. In addition, the possible influence of odors from soiled bedding material from the pups' home cage on emotionality was examined. Our inquiry revealed that the tactile and thermal, but not olfactory, stimulus dimensions of the anesthetized dam were important determinants of the dam's fear-reducing capacity. The presence of odors from the home cage had no effect on the emotional state of the animal. These results are discussed in relation to the hypothesis that stimuli from the home environment (e.g., home odors) enhance learning in young animals by reducing the stress that the animals experience when separated from their home cage and placed in an unfamiliar environment.
\end{abstract}

Over the past decade it has become increasingly evident that young animals' performance on a variety of learning and memory tasks can be enhanced if the animals are trained and tested in the presence of familiar contextual stimuli from their home environment. For example, Rudy and Cheatle (1977) gave 2-day-old rats an odor-illness pairing (lemon- $\mathrm{LiCl}$ ) in the presence of their littermates and found that the pups retained this odor aversion when tested 4 days later. The presence of littermates during training was later found to be a necessary condition for this odor aversion to be maintained (Smith \& Spear, 1978).

Smith and Spear (1978) demonstrated that although the presence of soiled home-cage nesting material facilitated acquisition of a passive avoidance task and increased spontaneous alternation behavior in 16-day-old rat pups, it did not affect adult behaviors during these same tasks. Subsequent reports have corroborated these initial findings. The presence of soiled bedding material from the home nest facilitates learning and retention of a simple active avoidance (Misanin, Lariviere, Turns, Turns, \& Hinderliter, 1986), as well as a spatial discrimination task to escape footshock (Smith \& Spear, 1981; Wigal, Kucharski, \& Spear, 1984). While the important component of home odors appears to be the familiarity of the stimulus

This research was supported by U.S. Public Health Service Grant MH01562 to Byron A. Campbell. Michael A. Siegel, now deceased, was supported by National Institute of Mental Health Training Grant MH15799. Rick Richardson was supported by National Research Service Award AG-05417 from the National Institute on Aging. Reprint requests should be sent to Byron A. Campbell, Department of Psychology, Princeton University, Princeton, NJ 08544. rather than the presence of a maternal pheromone (Wigal et al., 1984), the mechanism by which home stimuli enhances learning in young animals is yet to be determined.

The presence of familiar contextual stimuli from the home environment (e.g., an anesthetized conspecific, home odors) have been shown to reduce the isolationinduced behavioral arousal of young rats housed in an unfamiliar environment for either $16 \mathrm{~h}$ (Randall \& Campbell, 1976) or 6 h (Campbell \& Raskin, 1978). Similar findings have been reported by Hofer and Shair (1980), who found that the presence of an anesthetized dam or littermate reduced the isolation-induced ultrasonic vocalizations (USV) in 14-day-old rat pups.

These findings have led to the proposal that such stimuli reduce the stress that the young animal experiences when separated from its home environment and placed in unfamiliar surroundings. This reduction of stress may enhance the capacity of the young animal to process salient information and thus learn more proficiently (Misanin et al., 1986). Because the stress-reduction hypothesis is so intuitively appeali $\mathrm{g}$, and because it has such potentially broad implications for understanding the differences in learning that occur between pre- (15- to 20-day-old) and post- (21- to 25-day-old) weanling rats, we decided to investigate the effects of familiar contextual stimuli further, using heart rate (HR) as a simple and direct measure of the distress elicited by unfamiliar environments.

The intent was to identify those stimuli that are effective in attenuating the increase in HR normally produced by exposing animals to an unfamiliar test environment. Recent research in our laboratory (Richardson, Siegel, \& Campbell, in press) had shown that the presence of an 
anesthetized lactating dam was remarkably effective in lowering HR in rats 16 to 30 days of age but not in 60 day-olds. Our first hope was to show that the familiar home-cage odors that are so effective in facilitating learning in the 16-day-old rat also produce a sharp reduction in $H R$ in animals of that age. We further expected that the presence of familiar home-cage odors would be relatively ineffective in reducing HR in 28-day-olds, an age at which the presence of those stimuli did not facilitate learning (Wigal et al., 1984). The implicit assumption was that home-cage odors would be a less effective contextual stimulus than the anesthetized dam, and therefore would lose its "calming" effect earlier in the developmental sequence.

HR was chosen for this research because it has been shown to be a particularly sensitive index of rapid changes in emotional state in both humans (Campos, 1976) and infrahuman species (Black, Fowler, \& Kimbrell, 1964; Candland, Pack, \& Matthews, 1967). In the 9-month-old human infant, for example, HR increases dramatically at the approach of a stranger and at the edge of a visual cliff (Campos, 1976). Similarly, placement of the infant rat in an unfamiliar environment produces rapid and longlasting increases in HR (Richardson, Siegel, \& Campbell, in press), vocalization (Hofer \& Shair, 1980), and corticosterone (Stanton, Wallstrom, \& Levine, 1987) levels, all of which are considered reliable measures of emotional distress. Furthermore, our technique for measuring HR in young animals allows us to implant the recording electrodes acutely and to obtain repeated samples over an extended period of time with a minimum disturbance to the animal.

\section{EXPERIMENT 1}

The purpose of Experiment 1 was to study the effect of olfactory stimuli emanating from an anesthetized dam on the HR of 16-day-old rat pups placed in an unfamiliar test situation. To accomplish this, we used an apparatus which allowed pups in one group to see and smell the dam, but prevented them from making physical contact with it.

\section{Method}

Subjects. Thirty experimentally naive male and female 16-dayold rat pups derived from the Sprague-Dawley strain bred and reared in the animal colony of the psychology department at Princeton University were used in this experiment. The day of birth was counted as Day 0 . All the litters were culled to 8 pups at 2 days of age and were left undisturbed until the day of experimentation. The pups were housed in $45 \times 24 \times 21 \mathrm{~cm}$ plastic rat cages with the dam, in a colony maintained on a 16:8 day:night cycle at $24 \pm 1^{\circ} \mathrm{C}$. Purina Rat Chow and water were available ad lib. No more than 3 animals from any one litter were used in any one condition.

A standard procedure in the breeding colony at Princeton University is to sacrifice dams after two maternal cycles. The dams that were about to be sacrificed served as our maternal safety stimulus. All the dams were pretreated with $0.1 \mathrm{cc}$ atropine sulfate $(.8 \mathrm{mg} / \mathrm{cc}$, subcutaneously) $15 \mathrm{~min}$ prior to anesthetization by injection (interperitoneal) of $40 \mathrm{mg} / \mathrm{kg}$ pentobarbital. Once anesthetized, the dams were gently placed on their sides along the rear wall of the test chamber. The pups tested in the presence of the dam were placed directly on the dam at the start of each session.

HR recording procedure. HR was recorded through two transcutaneous stainless steel electrodes in the form of modified miniature safety pins attached to 32 gauge Teflon-coated stainless steel wire (Alpha 2840/7). One electrode was implanted dorsally, at the nape of the neck, and the other was implanted ventrally, anterior to the urogenital region. Neither the HR electrodes nor the attached leads appeared to interfere with the pups' movement. The cardiac potential thus obtained was amplified by a Grass model P15 amplifier. The R spike activated a Coulbourn Instruments Schmitt trigger. This pulse was fed to a Commodore PET microprocessor that measured the interbeat interval (IBI) to the nearest millisecond and stored that information on floppy diskettes for further analysis. The cardiac signal was continuously displayed on a Hitachi oscilloscope (Model V-212).

Each animal was removed from the home cage and brought to the test chamber where the electrodes were inserted. The animals were immediately placed in the test apparatus. This procedure took approximately $30 \mathrm{sec}$.

Apparatus and Procedure. The pups were tested for $30 \mathrm{~min}$ in a small Plexiglas chamber $(29 \times 20 \times 15 \mathrm{~cm})$, which was divided by a stainless steel grid barrier (spaced $1.0 \mathrm{~cm}$ apart) into a compartment where the pup was placed $(19 \times 20 \times 15 \mathrm{~cm})$ and a smaller compartment where an anesthetized dam could be situated. The Plexiglas chamber was situated inside a $128 \times 77 \times 48 \mathrm{~cm}$ sound- and light-attenuating chamber (IAC), maintained at an ambient temperature of $24 \pm 1^{\circ} \mathrm{C}$. Dim illumination, provided by two 6-W nightlights placed in the corners of the apparatus, gave sufficient light to observe the animals' behavior.

The pups were equally divided into three groups, which were placed in the Plexiglas chamber either (1) alone, (2) with the dam accessible (the dam and pup in the same compartment), or (3) with the dam inaccessible (the dam on the other side of the barrier). In the inaccessible condition, the pup could smell and see the dam but could not physically interact with her.

Behavioral observation. To examine the possible influence of somatomotor activity on HR, behavior was observed and scored during Minutes 0-5, 10-15, and 25-30 of the 30-min test. Each 5 -min observation period was divided into $1030-\mathrm{sec}$ bins, during which the general locomotor activity of the pup was scored on a 3-point rating scale. The criteria for scoring were as follows: $0=$ movement not sustained for longer than $5 \mathrm{sec} ; 1=$ movement sustained for at least $5 \mathrm{sec}$ but no more than $15 \mathrm{sec} ; 2=$ movement sustained for longer than $15 \mathrm{sec}$ and accompanied by grooming, walking and/or rearing.

\section{Results and Discussion}

Figure 1 shows that the mere presence of an inaccessible dam was not sufficient to reduce the increase in HR that a young animal typically displays when exposed to an unfamiliar environment. Throughout the entire 30-min test period, the pups tested either alone or in the presence of the inaccessible dam had much higher HRs than did those tested in the presence of an accessible dam.

An analysis of variance yielded significant effects of both group $[F(2,27)=26.20, p<.01]$ and time $[F(2,54)$ $=3.77, p<.05]$. There was no group $\times$ time interaction $(F<1.5)$. Newman-Keuls tests confirmed that the animals placed in the test apparatus and able to contact the anesthetized dam had significantly lower HRs throughout the test $(p<.05)$ than did groups tested either alone or in the presence of the inaccessible dam. These latter two groups did not differ from each other. 


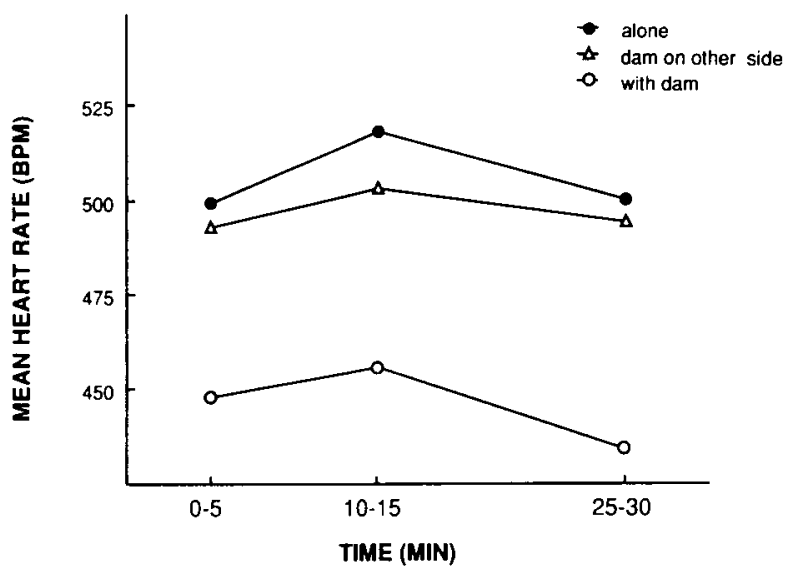

Figure 1. Mean HR (beats per minute) of 16-day-old rats tested alone (filled circles), with an accessible anesthetized dam (open circles), or with an inaccessible anesthetized dam placed behind a grid barrier (open triangles) during a 30-min exposure to an unfamiliar environment.

In contrast to the HR data, there was no group effect on behavioral activity. As can be seen in Figure 2, all three groups showed high levels of activity during the first $5 \mathrm{~min}$ of the test session. During this time, the animals tested with an accessible dam engaged in dam-directed probing behaviors, whereas the animals in the other groups displayed more generalized exploratory behaviors. As the test continued, the animals in all three groups became less active.

An analysis of variance performed on the activity data confirmed that there were no reliable differences among the groups $(F<1.0)$. While activity reliably decreased over the course of the test $[F(2,54)=26.63, p<.01]$, there was no group $\times$ time interaction $[F(4,54)<1.0]$.

In Experiment 1, the HR of pups able to interact physically with the dam was reliably lower than the HR of animals tested alone or in the presence of an inaccessible

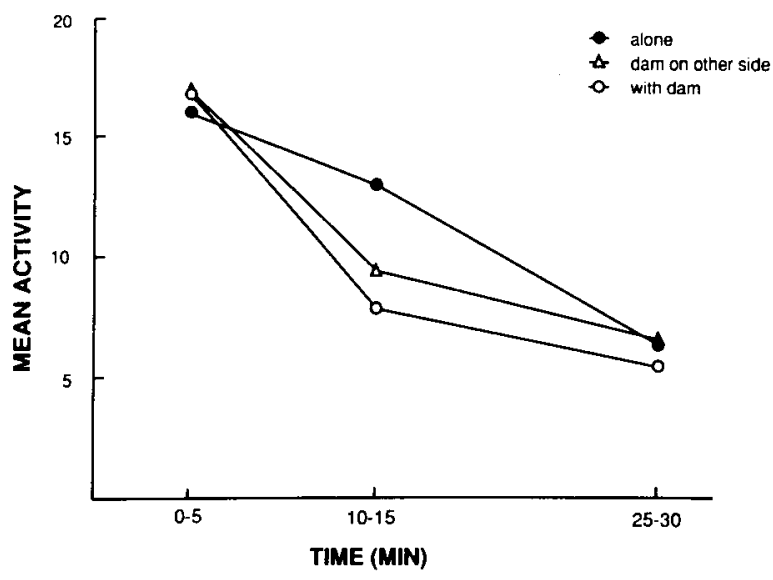

Figure 2. Mean level of activity of 16-day-old rats tested alone (filled circles), with an accessible anesthetized dam (open circles), or with an inaccessible anesthetized dam placed behind a grid barrier (open triangles) during a 30-min exposure to an unfamiliar environment. dam. Interestingly, the cardiac activity of the latter two groups did not differ. This indicates that the olfactory component of the dam is not sufficient to reduce the elevated HR typically exhibited by young animals when placed alone in an unfamiliar environment.

By the end of the 30-min test session, all the animals were relatively quiescent behaviorally (Figure 2), but as shown in Figure 1, those tested both alone and with an inaccessible dam were in fact experiencing more distress, as indexed by higher $H R$, than animals tested with an accessible dam. Thus, while the emotional state of the human infant is often discernible from the child's facial expression (Campos, Emde, Gaensbauer, \& Henderson, 1975), autonomic indices are useful for the determination of fear in animals, whose emotional state may be difficult to infer from their behavior.

\section{EXPERIMENT 2}

In Experiment 1 we demonstrated that the olfactory attributes of the dam were not effective in reducing the elevated levels of HR seen in young animals exposed to an unfamiliar environment. The purpose of Experiment 2 was to test the influence of a more concentrated olfactory stimulus-soiled bedding material from the animals' home cage-on the HR of the young animal placed in an unfamiliar environment. Since odors from the home environment have been shown to have a profound influence on the behavior of young animals in a variety of situations, apart from learning (e.g., Campbell \& Raskin, 1978; Leon \& Moltz, 1972), we expected that 16-dayold rat pups tested in the presence of 5-day-old soiled bedding material from their home cage would exhibit lower HR than those tested with clean shavings. As mentioned previously, the important component of home odors is their familiarity (Wigal et al., 1984). Thus, to make the testing situation more similar to their home environment, some animals were placed directly in the shavings while others were tested on a grid floor situated over the bedding material.

\section{Method}

Subjects. Forty 16-day-old preweanling rat pups were used as subjects in this experiment.

Apparatus and Procedure. All pups were tested in a $22 \times 22 \times 50 \mathrm{~cm}$ topless Plexiglas cage, located inside a sound- and light-attenuating chamber. A 1-liter beaker of either clean shavings or 5-day-old soiled shavings from the subjects' home cage was spread evenly on the floor of the apparatus. Half the animals were placed directly in the shavings, while half were tested on a grid floor $(2 \mathrm{~mm}$ grids spaced $0.5 \mathrm{~cm}$ apart) mounted approximately $1 \mathrm{~cm}$ over the shavings. The pups were thus tested for $90 \mathrm{~min}$ under four conditions: in soiled shavings; in clean shavings; on a grid floor with soiled shavings underneath; on a grid floor with clean shavings underneath. HR and behavioral activity were measured during Minutes 0-5, 25-30, 60-65, and 85-90.

\section{Results and Discussion}

The mean HRs for the subjects tested in Experiment 2 are displayed in Figure 3. The animals tested on the grid 


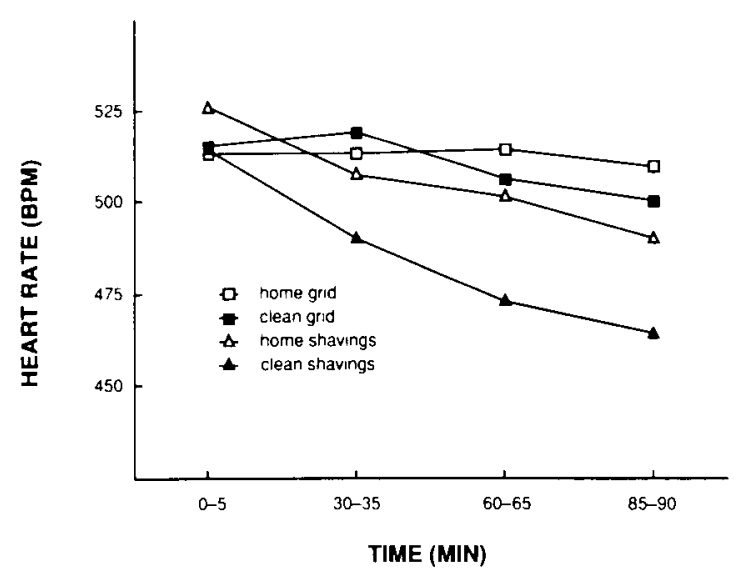

Figure 3. Mean HR (beats-per-minute) of 16-day-old rats tested in the presence of clean (filled symbols) or five-day-old soiled (open symbols) bedding materials, during a 90 -min exposure to an unfamiliar environment. Animals were tested either directly in the shavings (triangles) or on a grid floor over the shavings (squares).

floor, regardless of the type of shavings underneath, maintained high HRs throughout the 90 -min test. For the pups that were tested in the shavings, only the group tested in the clean shavings showed a reduction in HR. An analysis of variance yielded significant main effects of shavings $[F(1,36)=5.01, p<.05]$, floor $[F(1,36)=9.12$, $p<.01]$, and time $[F(3,108)=15.47, p<.01]$. The only significant interaction was floor $\times$ time $[F(3,108)$ $=6.78, p<.05]$. This interaction can be attributed to the reduction in HR of the pups tested in the clean shavings. Newman-Keuls tests revealed that the animals placed directly in the clean shavings had significantly lower HRs during the latter portions of the test. Specifically, at the 60-65-min time interval, pups tested in the clean shavings had reliably lower HRs than those tested on the grid in the presence of home shavings. At the 85-90-min time interval, all the animals tested on the grid, regardless of

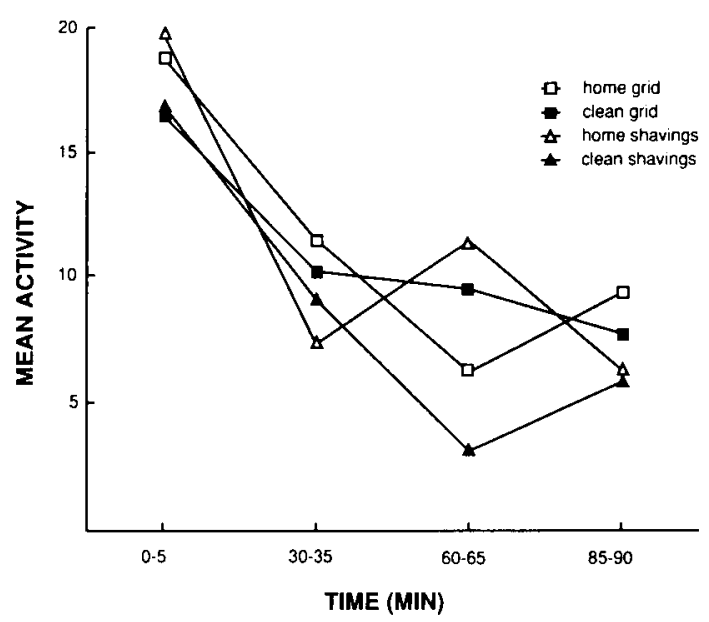

Figure 4. Mean level of activity of 16-day-old rats tested in the presence of clean (filled symbols) or five-day-old soiled (open symbols) bedding material, during a 90-min exposure to an unfamiliar environment. Animals were tested either directly in the shavings (triangles) or on a grid floor over the shavings (squares). type of shavings, were reliably different from those tested in clean shavings $(p s<.05)$.

As in Experiment 1, animals in all groups showed heightened locomotor activity when they were first placed in the unfamiliar testing situation. Their activity then decreased as the test progressed. These results can be seen in Figure 4. The only significant main effect found in the analysis of this data was of time $[F(3,180)=23.44$, $p<.01]$. All other main effects and all interactions were not found to be significant (all $F \mathrm{~s}<1.0$ ).

The results of Experiment 2 show that familiar contextual odors from the home cage do not affect the HR of young animals placed in an unfamiliar environment. This outcome is quite surprising, considering that odors from the home environment have been found to influence behaviors thought to be indicative of emotionality such as isolation-induced hyperactivity (Campbell \& Raskin, 1978) and isolation-induced ultrasonic vocalizations (Conely \& Bell, 1978; but see Hofer \& Shair, 1980).

Our original goal in Experiment 2 was at first to demonstrate that while home odors reduced HR in 16-day-old animals, they would be ineffective in reducing the HR of older pups. Since we failed to find that olfactory cues from the home nest reduced HR in 16-day-olds, we abandoned this course of action and focused our attention on the salient cues of the dam that might be important in calming the immature animals.

The reduction of HR seen in animals tested in the clean shavings was a totally unexpected outcome, which may have resulted from a qualitative difference between the home and clean shavings. The soiled home-cage shavings were slightly damp and packed down, whereas the clean shavings, which were fluffy, enabled the animals to burrow underneath. The animals tested in the soiled shavings always rested on top of them, whereas those tested in the clean ones were usually fully covered by them. Therefore, the clean shavings may have provided important tactile and/or thermal cues that reduced HR in the preweanling rat. In Experiment 3 we therefore examined the thermotactile stimulus dimensions of a surrogate dam, in order to determine what role they might play in an anesthetized dam's ability to reduce the distress experienced by preweanling rats placed in an unfamiliar environment.

\section{EXPERIMENT 3}

The original purpose of the present investigation was to demonstrate that home odors facilitate learning by reducing the distress that young animals experience when separated from their home environment and placed in unfamiliar surroundings. The findings of Experiments 1 and 2 led us to conclude that home odors facilitate learning via some mechanism other than stress reduction. However, the question remained as to what components of the dam were responsible for lowering the HR of immature animals tested in an unfamiliar environment.

Previous research by Hofer and Shair (1980) suggested that a combinatiun of sensory cues of a conspecific (e.g., tactile, thermal, etc.), rather than any one by itself, is ef- 
fective in reducing isolation-induced ultrasonic vocalizations. In the following experiment, animals were therefore tested with a heated surrogate stimulus that varied in tactile properties. Based on Hofer and Shair's (1980) findings, it was our expectation that pups would show graded levels of HR, depending on the surrogate they were tested with. The pups tested with the surrogate that most resembled a rat (warm and furry) whould show the lowest HR, while the cardiac activity of animals tested with a warm smooth surrogate would be no different than those tested alone.

\section{Method}

Subjects. Fifty 16-day-old male and female rats were used as subjects in this experiment.

Apparatus and Procedure. The animals were tested in the apparatus that was used in Experiment 2. The subjects were equally divided into five groups that were tested either (1) alone, (2) with an anesthetized dam, or (3) with a heated surrogate stimulus covered with plastic, cloth, or fur. The surrogate consisted of an aluminum tube $5 \mathrm{~cm}$ in diameter and $19 \mathrm{~cm}$ long, covered with one of the following materials: synthetic fur (with a nap approximately $.5 \mathrm{~cm}$ long), $100 \%$ cotton cloth, or plastic. A heat source consisting of a low resistance heat coil was mounted in the center of the tube throughout its entire length. Surface temperature was maintained at $35^{\circ} \pm 1^{\circ} \mathrm{C}$. The temperature of the surrogate stimulus during the test was regulated by means of a thermistor probe (YSI), connected to a Thermistemp Temperature Controller (YSI) and inserted between the various covering materials and the tube. The heat source was powered by a Sorensen DC power supply. The surrogate was heated 30 min prior to onset of the test. At the start of each test, the pup was removed from the home cage, implanted with the electrodes, and placed in the test chamber. The animals tested with the anesthetized dam or one of the surrogate stimuli were placed directly on the object at the start of the test.

\section{Results and Discussion}

The mean HRs for the subjects in Experiment 3 are shown in Figure 5. The pups tested alone had the highest

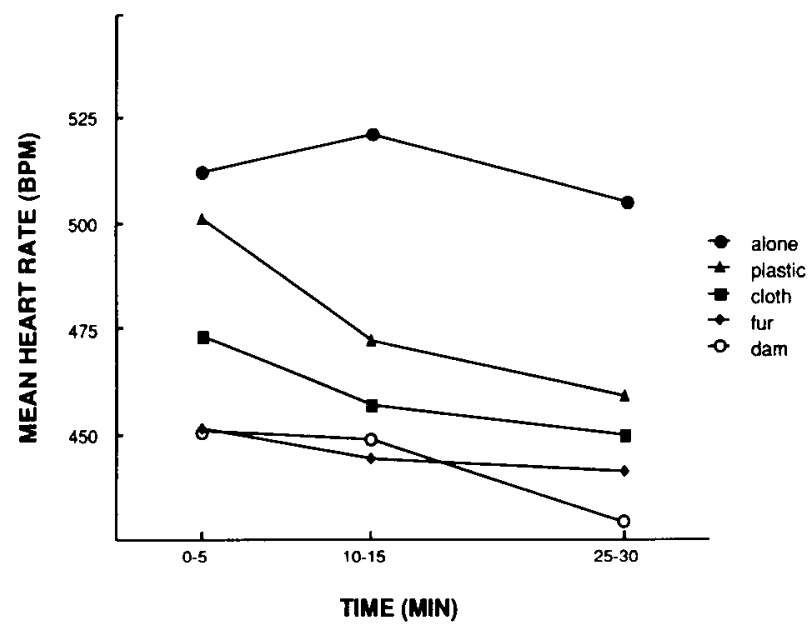

Figure 5. Effect of various types of heated $\left(35 \pm 1^{\circ} \mathrm{C}\right)$ surrogate stimuli on the HIR of 16-day-old rats during a 30-min exposure to an unfamiliar environment. For comparison, one group of animals was tested alone (filled circles), and another was tested in the presence of an anesthetized dam (open circles).

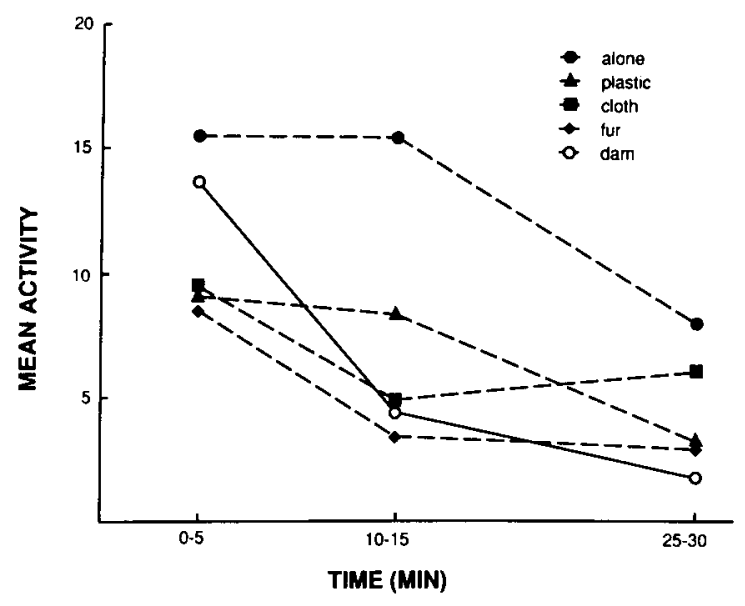

Figure 6. Effect of various types of heated $\left(35 \pm 1^{\circ} \mathrm{C}\right)$ surrogate stimuli on the mean level of activity of 16-day-old rats during a $30-$ min exposure to an unfamiliar environment. For comparison, one group of animals was tested alone (filled circles), and another was tested in the presence of an anesthetized dam (open circles).

heart rate, followed by the plastic, cloth, dam, and fur conditions, respectively. The HR of the plastic- and clothsurrogate groups decreased as the test progressed. An analysis of variance showed the main effects of both groups $[F(4,45)=5.97, p<.01]$, and time $[F(2,90)=$ $8.85, p<.01]$ to be significant. There was no group $X$ time interaction $[F(2,90)<1.2]$.

Newman-Keuls tests revealed that the HRs of animals tested with the fur surrogate and anesthetized dam were significantly lower during the first $5 \mathrm{~min}$ of the test as compared with the HRs of animals tested alone $(p<.05)$ or in the presence of the plastic surrogate $(p<.06)$. During subsequent time periods, the subjects tested with any of the surrogate objects or with an anesthetized dam had significantly lower HRs than the subjects tested alone $(p<.05)$.

The activity data for Experiment 3 are displayed in Figure 6. Although in general the animals tested alone were more active than those tested with one of the surrogate stimuli or the anesthetized dam, the activity of all groups decreased as the test progressed. An analysis of variance showed that the main effects of both groups $[F(4,45)=7.00, p<.01]$ and time $[F(2,90)=29.71$, $p<.01]$ were significant, as was the group $\times$ time interaction $[F(8,90)=2.62, p<.01]$.

As with Experiments 2 and 3, differences in motor activity cannot account for the group differences in cardiac activity. During the first 5 min of the test, a NewmanKeuls analysis yielded no significant differences among the activity levels of any of the groups (Figure 6), yet during this time interval, animals tested with both the anesthetized dam and the fur surrogate had reliably lower HRs than did those tested alone or with the plastic-covered surrogate (Figure 5). Thus, no simple cardiac-somatic coupling explanation can account for these findings.

The results of Experiment 3 suggest that the tactile and thermal stimulus dimensions of the dam were major de- 
terminants of her capacity to lower the HR of preweanling rat pups exposed to an unfamiliar environment. Note that the tactile properties of the surrogate were important in initially reducing the heightened levels of cardiac activity, but that shortly thereafter, thermal attributes gained in prominence.

\section{GENERAL DISCUSSION}

The results of our investigation show that thermotactile (Experiment 3 ) rather than olfactory (Experiment 1) attributes of the dam are instrumental in reducing the unconditioned emotional response elicited when young preweanling animals are removed from their home cage and placed in an unfamiliar environment. These results confirm and extend our previous findings, which have demonstrated that the presence of an anesthetized lactating dam greatly reduces the heart rate of preweanling rat pups placed in an unfamiliar situation (Richardson et al., in press).

In Experiment 1, we showed that maternal contact, rather than the sight or smell of the dam, is the crucial factor that lowers the HR of rat pups tested in an unfamiliar environment. These results agree with a recent experiment (Stanton, Wallstrom, \& Levine, 1987) that elegantly demonstrated that maternal contact reduced the elevated levels of plasma corticosterone detected when preweanling rats were placed alone in an unfamiliar environment for a 30 -minute test. This effect was not seen in pups prevented from making physical contact with the dam.

When animals were tested in the presence of a heated surrogate stimulus that varied in tactile properties (Experiment 3), the initial cardiac response was related to the tactile component of the surrogate. The animals tested with the surrogate that provided the least tactile comfort, plastic, exhibited an HR similar to that of the animals placed in the apparatus alone, while the HR of the animals tested with the surrogate that provided the most tactile comfort, synthetic fur, was similar to that of the animals tested in the presence of an anesthetized dam. As the test progressed, it appeared that the thermal properties of the surrogate gained prominence, resulting in reduced HRs in all groups except those tested alone (Figure 5).

These results are strikingly similar to those reported by Hofer and Shair (1980), who examined the influence of a variety of surrogate stimuli on the ultrasonic vocalizations of 14-day-old rat pups tested during a 6-min period of isolation. Hofer and Shair observed that the efficacy of a surrogate stimulus in reducing the USV of isolated pups depended on several cues rather than on one in particular. Specifically, the presence of a heated, furry surrogate stimulus was as effective as an anesthetized conspecific in reducing the USV whereas a warm, smooth surrogate was incapable of reducing the distress of the young animals. In contrast to Hofer and Shair's findings, our data in Experiment 3 indicate that as the test progressed, the thermal attributes of the smooth surrogate became more salient, resulting in a reduction of $H R$ in those subjects tested with the plastic surrogate. Thus we have extended Hofer and Shair's (1980) findings by showing that although at first no one cue (e.g., heat) is effective in reducing the distress of young rats, with the passage of time a salient stimulus such as warmth will gain more influence over the distress of young animals separated from their home cage and placed in unfamiliar surroundings.

Taken together, the findings that maternal contact reduces the level of fear or distress and that such a reduction in emotionality can be attributed to the thermal and tactile attributes of the dam recall the importance of "contact-comfort" in the early social attachment of infant rhesus monkeys (Harlow, 1958). In addition, the results of this investigation are compatible with the research on preweanling rats that shows that both the tactile and/or thermal attributes of a surrogate stimulus are important properties in such situations as the induction of conspecific huddling (Campbell \& Raskin, 1981) and the promotion of olfactory preferences (Alberts \& May, 1984).

Compared with the previous research that shows that home nest odors facilitate learning in the pre-weanling rat, our research unexpectedly revealed that neither the olfactory component of the dam (Experiment 1) nor the odor from home-cage shavings (Experiment 2) had any effect on the cardiac activity of the rat pups. Our findings agree with those of Hofer and Shair (1980) and Stanton et al. (1987) which suggest that neither the home cage nor the olfactory attributes of the dam are effective in reducing levels of distress exhibited by pups placed alone in unfamiliar surroundings. Taken together, these results indicate that home odors do not reduce the emotional stress that young animals experience when they are placed in an unfamiliar environment. Thus it appears that familiar olfactory stimuli from the home environment facilitate learning via some mechanism other than stress reduction.

One alternative explanation is that familiar home stimuli act on more cognitive mechanisms, such as sensory information processing. Perhaps home stimuli enhance the stimulus-processing capacity of young animals, which in turn results in better learning. However, in a recent investigation in our laboratory, we found that neither home odors nor maternal presence enhanced either behavioral or cardiac orienting responses (frequent measures of information processing) shortly after 16-day-old rat pups were placed in an unfamiliar environment (Siegel, Richardson, \& Campbell, 1986). These findings suggest that it is not likely that home odors enhance learning by augmenting the initial stages of sensory information processing. It still may be the case, however, that these stimuli do affect some higher order cognitive mechanism.

Another alternate explanation (Smith \& Spear, 1978, 1981; Misanin et al., 1986) stems from the fact that most studies that examine the effects of home odors on the learning capacity of young animals employ aversively motivated tasks. Perhaps the apparent enhancement of 
learning produced by these stimuli is due to the fact that home odors influence the young animals' initial response to and/or subsequent recovery from a stressor (e.g., shock). In support of this possibility, research has found that home odors attenuate the wall-climbing response to footshock in 12-day-old rats (Barrett, Caza, Spear, \& Spear, 1982). Whether home stimuli affect the developing organisms' response to stressors in other situations awaits further investigation.

In sum, the main focus of the present research was to determine both the important stimulus components of the dam and the other contextual stimuli from the home nest that modulate the unconditioned fear elicited by separation from the home cage and placement in an unfamiliar environment. We found that the tactile and thermal properties of the dam play a major role in calming young animals in this situation. Neither the olfactory attributes of the dam nor the presence of soiled bedding material from the animals' home cage had any noticeable effects on the emotional response of young animals placed in an unfamiliar environment. Thus, it appears that home shavings act to facilitate learning through some mechanism other than stress reduction when young animals are isolated in unfamiliar surroundings.

\section{REFERENCES}

Alberts, J. R., MAY, B. (1984). Nonnutritive, thermotactile induction of filial huddling in rat pups. Developmental Psychobiology, 17, 161-181.

Barrett, B. A., Caza, P. Spear, N. E., Spear, L. P. (1982). Wall climbing, odors from the home nest and catecholaminergic activity in rat pups. Physiology \& Behavior, 29, 501-507.

Black, R. W., Fowler, R. I., \& Kimbrell, G. (1964). Adaptation and habituation of heart rate to handling in the rat. Journal of Comparative \& Physiological Psychology, 57, 422-425.

CAmpBell, B. A., RAskin, L. A. (1978). Ontogeny of behavioral arousal: The role of environmental stimuli. Journal of Comparative \& Physiological Psychology, 92, 176-184.

Campbell, B. A., Raskin, L. A. (1981). Canalization of arousal in the preweanling rat: Effects of amphetamine on aggregation with surrogate stimuli. Developmental Psychobiology, 14, 127-137.

Campos, J. J. (1976). Heart rate: A sensitive tool for the study of emotional development in the infant. In L. P. Lippsitt (Ed.), Developmental psychobiology. Hillsdale, NJ: Erlbaum.
Campos, J. J., Emde, R., Gaensanuer, T., Henderson, C. (1975). Cardiac and behavioral interrelationships in the reactions of infants to strangers. Developmental Psychobiology, 11, 589-601.

Candland, D. K., Pack, K. D., Matthews, T. J. (1967). Heart rate and defecation frequency as measures of rodent emotionality. Journal of Comparative \& Physiological Psychology, 64, 146-150.

Conely, L., \&ELL, R. W. (1978). Neonatal ultrasounds elicited by odor cues. Developmental Psychobiology, 11, 193-197.

HARLow, H. F. (1958). The nature of love. Scientific American, 200. 68-74.

Hofer, M. A., \& Shair, H. N. (1980). Sensory processes in the control of isolation-induced ultrasonic vocalizations by 2 -week-old rats. Joumal of Comparative \& Physiological Psychology, 94, 271-279.

LEON, M., \& Moltz, H. (1972). Maternal pheromone: Discrimination by preweanling albino rats. Physiology \& Behavior, 14, 683-686.

Misanin, J. R., Lariviere, N. A., Turns, A. E., Turns, L. E., HinderLITER, C. F. (1986). The effect of home cage stimuli on acquisition and retention of an active avoidance response in previsual rats. Developmental Psychobiology, 19, 37-47.

Randall, P. K., CAMPBELL, B. A. (1976). Ontogeny of behavioral arousal in rats: Effects of maternal and sibling presence. Journal of Comparative \& Physiological Psychology, 90, 453-459.

Richardson, R., Siegel, M. A., Campaell, B. A. (in press). Effect of maternal presence on the fear response to an unfamiliar environment as measured by heart rate in rats as a function of age. $\mathrm{De}$ velopmental Psychobiology.

Rudy, J. W., \& Cheatle, M. D. (1977). Odor aversion learning in neonatal rats. Science, $198.845-846$.

Siegel, M. A., Richardson, R., Campeell, B. A. (1986). Sensory information processing during adaptation to an unfamiliar environment in the developing rat. Intermational Society for Developmental Psychobiology: Abstracts, (p.59).

Smith, G. J., \& SPEAR, N. E. (1978). Effects of home environment on withholding behaviors and conditioning in infant and neonatal rats. Science, 202, 327-329.

SMITH, G. J., \& SPEAR, N. E. (1981). Home environmental stimuli facilitate learning of shock escape spatial discrimination in rats 7-11 days of age. Behavioral \& Neural Biology, 31, 360-365.

Stanton, M. E., Wallstrom, J., \& Levine, S. (1987). Maternal contact inhibits pituitary-adrenal stress responses in preweanling rats. Developmental Psychobiology, 20, 131-145.

Wigal. T., KUCharski, D., SPEAR, N. E. (1984). Familiar contextual odors promote discrimination leaming in preweanling, but not older rats. Developmental Psychobiology, 17, 555-570.

(Manuscript received January 25, 1988; revision accepted for publication May 10, 1988) 